\title{
4 \\ Revaluing Pots: Wanigela Women and Regional Exchange
}

\author{
Elizabeth Bonshek
}

\section{Revaluing pots: Wanigela women and regional exchange}

The women of Wanigela are known throughout Collingwood Bay, Papua New Guinea (PNG), for making cooking pots (baitab nokwat) that are exchanged widely within the region. ${ }^{1}$ The clay pots have a distinctive design: as a minimum, a series of applied lines arranged in undulating patterns located around the rim or, more extensively, over the body of the pot, depending on its type. Baitab nokwat, the form used in exchanges, characteristically carry incised designs on the body with the applied wavy line motif confined to the rim. In the past, girls would have grown up watching their mothers skilfully manipulate the clay they had collected to make the vessels needed to carry and store water (simon); to eat or serve with (sewaf, ramo); to participate in ceremonial feasting (sabed); to cook with (baitab nokwat), or use as objects of exchange.

\footnotetext{
1 There are four local languages (tok ples) spoken in Wanigela: Ubir and Oyan are Austronesian languages; Onjob and Aisor are non-Austronesian. Ubir is the lingua franca of Wanigela. However, it is not unusual for Wanigelans to speak Maisin, the tok ples of their southern and northern neighbours, as well as Korafe (spoken in Tufi) and Miniafi (also to the north). Most men also speak Tok Pisin, Papua New Guinea's national language. However, Tok Pisin is not spoken widely by many of the senior women, who speak English instead (also a national language, along with Motu). Henceforth Ubir language words will be used in the text unless indicated otherwise.
} 
While most Wanigela women today have replaced clay pots for aluminium ones made in China and purchased from trade stores, baitab nokwat remain in use in longstanding regional exchanges within Collingwood Bay for canoes, hunting dogs, string bags, mats and barkcloth-the latter required by Wanigela women for festive dancing. Baitab nokwat feed into secondary exchanges and have been recorded at Agaon on the inland border of Milne Bay Province and Central Province (Busse, Araho and Baiva 1991; see also Hermkens this volume).

In the past, baitab nokwat were essential to the acquisition of nunug, shell necklaces of great symbolic value. Drawing upon their marital and kinship relationships with potters, men traded baitab nokwat for nunug, which were only obtainable as a result of long canoe voyages beyond Collingwood Bay to the south. Today, nunug expeditions have dropped out of Wanigela social memory: only the oldest men and women can remember them having occurred or have heard about them. And while the manufacture of pots for exchange within the Collingwood Bay region continues, the use of pots in all their forms within the Wanigelan home has reduced significantly, together with a marked reduction in the number of women who make pots (Bonshek 2008). This circumstance contrasts with a continued use of baitab nokwat by people from outside Wanigela seeking pots to maintain their social and ceremonial obligations.

Today, potters are mostly women aged 50 and over. They told me that they made pots because 'that is what Wanigelans do' (Bonshek 2008). For them, making pots manifested a unique aspect of their cultural production, although this was never directly articulated by them (or by their husbands and male relatives). In the past, learning to make pots was a part of a girl's upbringing (boys did not learn how to make pots). ${ }^{2} \mathrm{~A}$ vigorous potter would have stored up a supply of pots ready for exchanges or for other demands. But in the 1960s, as Wanigela women began to marry men who resided outside of the villages in town, their parents decided daughters who left Wanigela did not need to learn to make pots (Egloff 1974: 74). Perhaps as a result of this shift in practice, together with the availability of metal alternatives, the younger generation of Wanigela women associate pottery making with the activities of the senior

2 While this is still the case, in 2007 one man had begun to make pots in flower shapes and to sell these at the dive resort in Tufi. He told me that he could not make the traditional forms, which belonged to the women only, but that it was OK for him to create new forms. His wife, who was a potter, was supportive and helped him. 
women of their villages, although a small number of young women now see a potential to earn cash through pottery making. Thus the dynamics surrounding the continuing, if reduced, production of pots has been subject to changing circumstances as the result of interaction with global forces impacting upon local economies for some time (see Patterson and Macintyre 2011 for the critique of the nature of definitions of 'globalisation' and 'modernity'). However, in recent decades, further changes occurring outside of Wanigela, but from within the region, and stemming from new developments in the sustainable production of objects that Wanigelans exchange for, are contributing to the revaluing by Wanigelans of their pottery production. An insight into some of these changes was revealed in a pot exchange expedition made in 2002.

\section{An exchange expedition}

In 2002, I accompanied five potters from the villages of Wanigela on a pot-trading expedition. Phyliss, probably in her 60s, was regarded as a very experienced potter, having learnt her skills as a young girl. ${ }^{3}$ She had undertaken her last exchange trip about a year previously. On this trip, she had three pots she wanted to exchange. Carol, in her mid-50s, had started making pots only a couple of years prior to this trip, but was more than competent. She had four pots to exchange. Her last exchange trip, to the Maisin market in Uiaku some four hours' canoe trip south of Wanigela, occurred about three to four years previously; before she became a potter. She had travelled to Uiaku with her classificatory sister, and her sister's mother who had made the pots for that trip. Sarah had exchanged pots more recently, travelling with her husband to Uiaku to exchange 10 pots for barkcloth, which she then took to Port Moresby and sold for K50. ${ }^{4} \mathrm{Pim}$, a woman in her 60s, had not travelled away from Wanigela to exchange pots since she was a young girl. She remembered clearly that she had gone to Airara (a Maisin village to the south) with her sister (her father's sister's daughter), taking four pots to exchange for barkcloth. The last member of the group, Sharon, took two pots with her. She told me that she had not exchanged pots for 'many years'. Her last opportunity had been with her husband, who at the time had been a medical officer, which required him to go on patrol to various outstations in the region. She had accompanied him to Airara, and exchanged four

3 Real names are not used in this account.

4 Papua New Guinea's currency is the Kina (K). 
pots for barkcloth, which she had then given to Sister Helen Roberts, head of the medical clinic at Wanigela, who sent them on to Australia for sale. This was some time prior to 1991.5 Sharon had wanted the money to pay for her first-born daughter's school fees. The five women were active members of the Anglican Church and members of the Mothers' Union.

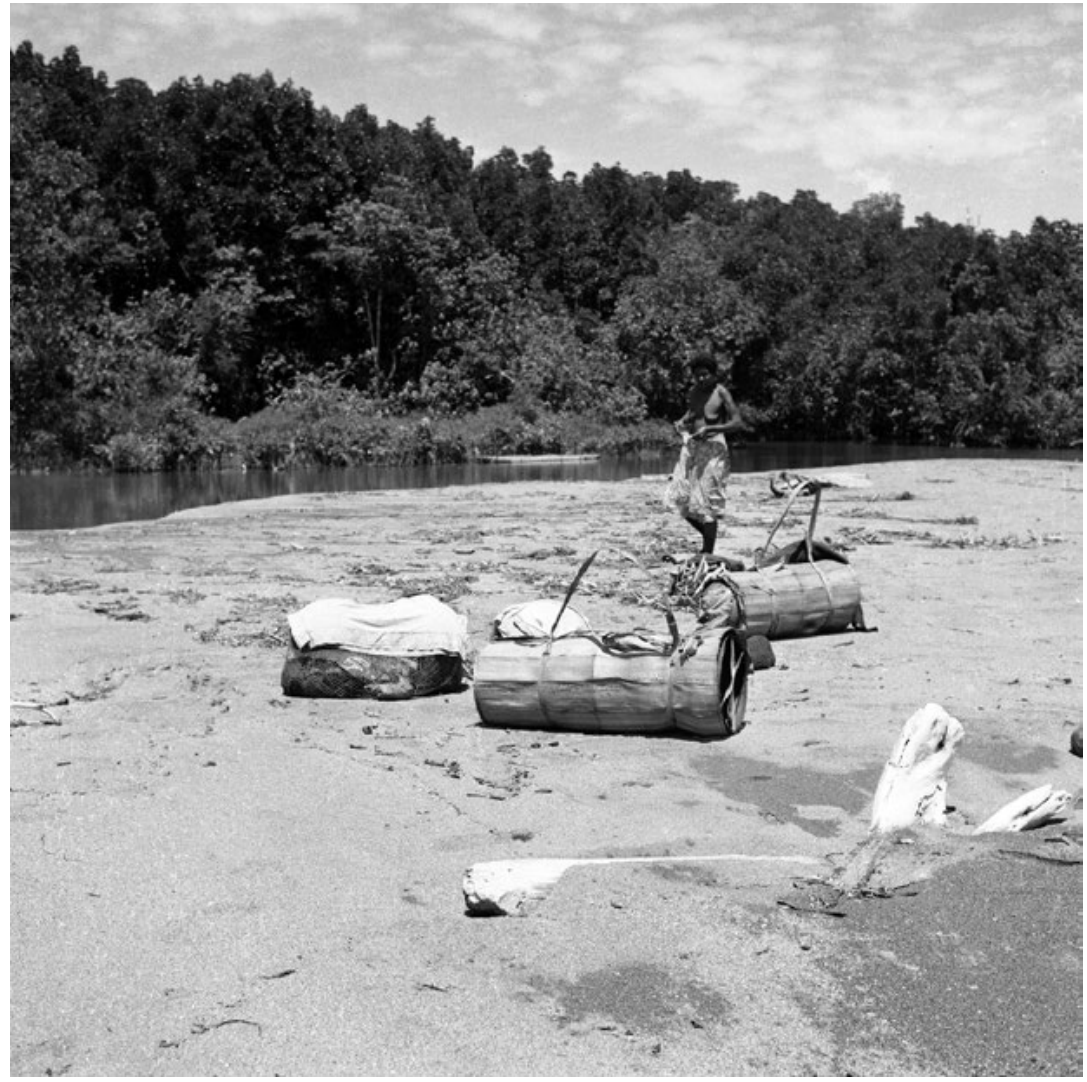

Figure 19. A woman with baitab nokwat packed ready for transport (1967). Each pack contains four pots wrapped and secured for carriage suspended from the head. On the 2002 expedition, the women did not use this carrying method, simply placing their pots packed inside string bags directly into the canoe

Source. Photographed by Brian Egloff, 1967, and used with his permission ${ }^{6}$

5 The date of this trip is uncertain: Sister Roberts died in 1991 but had been based in Wanigela since 1949.

6 My thanks to Brian Egloff for permission to use his photograph. 
The trip was organised for my benefit as well as theirs. I accompanied them as a newly arrived researcher interested in pottery and pot making. For them, the trip was a demonstration of the way to do things: how Wanigela women exchange pots. ${ }^{7}$ We climbed aboard a motor dinghy and set off for Airara, roughly 90 minutes to the south of Wanigela. ${ }^{8}$ Phyliss's son accompanied us, acting as escort for his mother and her companions. Ordinarily such a trip would have been undertaken by outrigger canoe or by walking, making the journey unachievable in a single day (Figure 19). On this occasion, the women walked from their homes inland in the bush, a two-hour walk for some of them, and stayed with relatives on the beach overnight, rising at dawn to commence the trip to Airara.

A note had been sent ahead of us through the Mothers' Union to announce our visit. When we arrived, we were met by six Airara women-one of whom was related to Carol (the women were related through their greatgrandmothers and they addressed themselves as 'cousin-sister' when using English). Sarah also knew one of the Airara women who had 'married into' Wanigela.

Having disembarked from the dinghy, we all sat on the 'visitors' platform' of the house belonging to one of the hosts, and the women chatted to one another for some time and we drank coconut juice. Then the Wanigela women placed their pots in front of where they were sitting. An Airara woman interested in a particular pot walked around the seated potter, and asked what the potter would like in exchange. The potters told their hosts whether they wanted ara (a man's barkcloth) or beber (a woman's barkcloth). These interactions continued, accompanied by earnest conversation.

Carol put out all four of her pots, and said that she wanted one ara for a large pot (which measured $28 \mathrm{~cm}$ wide $\mathrm{x} 22 \mathrm{~cm}$ high); changing to Maisin language, she added that she wanted one embobi (a woman's barkcloth) for a smaller pot. Pim also wanted one ara for her pot, and completed an exchange with a woman she knew, but to whom she was not related. Carol exchanged one large pot $(36 \mathrm{~cm}$ wide $\times 20 \mathrm{~cm}$ high) for two

7 I carried out fieldwork between 2001 and 2003 as a doctoral candidate at The Australian National University, Canberra; fieldwork in 2007 was undertaken as a research fellow on the Melanesia Art Project 2005-10, a joint project between the University of Cambridge and the British Museum, London, funded by the Arts and Humanities Research Council, UK. Subsequent research was undertaken as Assistant Professor, University of Canberra (2010-15).

$8 \quad$ I financed the motor boat for the trip. 
men's barkcloths. Sarah exchanged one pot for one ara with a woman with whom she was friends, but not related. Another woman took two of Sarah's pots, and agreed to give two women's barkcloths in exchange. At this point, the Wanigela women had not seen any of the barkcloth offered to them.

When the barkcloth was produced, there was consternation. It was not finished: the cloth had not been painted. This became a matter of great concern to the Wanigela women. The cloth shown to them had an outline of a design marked out in black but the red infill colour had not yet been applied. Carol became quite insistent that the 'Wanigela women' wanted finished barkcloth, which they needed for Lady Day some 18 days away. ${ }^{9}$ She said that she did not want to leave her pots without taking the barkcloth, and that she could not come back for them later. After about an hour, dealings appeared to be coming to a halt. And then someone suggested travelling on to Murua, the next village. But we all stayed where we were, betel nut arrived, and the women continued to sit around and chew.

Carol recommenced her negotiations for her barkcloth. She spoke to the mother of the woman who had made some of the barkcloth she was interested in, who, it transpired, was negotiating on the daughter's behalf. They agreed to exchange two pots for one ara and one beber, and Carol agreed to the cloth being sent up to Wanigela the following Thursday. Before we all moved on to Murua, Phyliss clinched her transaction, exchanging a beber for one pot with a Wanigela-born relation (husband's sister's daughter) and exchanged a second pot with an Airara woman she did not know.

At Murua, the exchanges were carried out on the platform of a canoe pulled up on the beach. Carol exchanged one pot with a relative (her cousin's wife) in exchange for one beber. At midday, we left Murua and went further south to Sinapara. Carol made enquiries here in Maisin, and we were directed to move on to Sinapa, a village further along. We left the dinghy and walked, heading for the house belonging to a woman called Violet. Carol and Violet were related: their great-great-grandfathers had been brothers. From here, word that Wanigela women had arrived and wanted to exchange pots for cloth was sent out to Koniasi, a small village to the south.

9 Lady Day falls in association with Easter in the Anglican Church calendar and is celebrated by members of the Mothers' Union. 
We sat around on Violet's visiting platform, waiting for the Koniasi people. Violet explained that it was a difficult time to get barkcloth because the drought had affected the growth of the mulberry trees (see Barker 2008 and Hermkens 2013 for barkcloth manufacture). As she spoke, she brought out a piece of barkcloth that she had tried to sell through the Maisin Integrated Conservation and Development project (MICAD, see Barker 2004, 2008; Hermkens 2013). MICAD exported Maisin barkcloth for sale to Port Moresby, the nation's capital, to provincial capitals, as well as internationally. She told us that MICAD had priced the piece at K44 and that she would accept two pots for this piece. No one took up the offer.

Sharon exchanged one pot for one beber with 'old Petra' who was an old friend of Carol's, but who did not know Sharon. Pim exchanged one pot for a barkcloth, and a second for a string bag with a woman called Polly, whom she did not know. Carol also exchanged a pot for a beber with Polly, who was a friend. Carol rejected another cloth because it was too small and would not fit around her waist, it did not have the proper edging and it was not painted. When the exchanges at Violet's house were concluded, we returned to the dinghy and headed back to Wanigela, arriving some two hours later.

\section{A continuing tradition}

The women on the expedition were amongst a small group in Wanigela for whom making pots continues to be a part of village life (Bonshek 2008). Their organisation and participation in the exchange expedition continued a tradition partially recorded by the first European arrivals to Wanigela in 1899, who observed not only how pots were made, but that pots were used in exchange with neighbouring villagers for barkcloth (Bonshek 1989). Pots continue to be made using the same method, a coiling technique that is distinctive to Wanigela (May and Tuckson 2000).

Only women make pots. They dig up the raw clay from the source, which is located on village land (wasa motob). Being on wasa motob, not clan land, anyone who is from Wanigela can access the clay, and having done so take it to a potter for the production of pots. Traditionally, the task of collecting clay was done early in the morning, at a time when the activity would be unlikely to be witnessed. While the removal of stones and debris from the clay in preparation for working and the construction of the pot itself might be carried out in view of family members, perhaps on the 
house verandah or in a purpose-built pot house, the firing of the vessels was a secretive affair to be undertaken in silence. It is at this time that the pots are in most danger. Cracking can take place during firing, so the potter 'cooks' the vessels in a secluded area where no one can see her working and where inadvertent speech presents no risk.

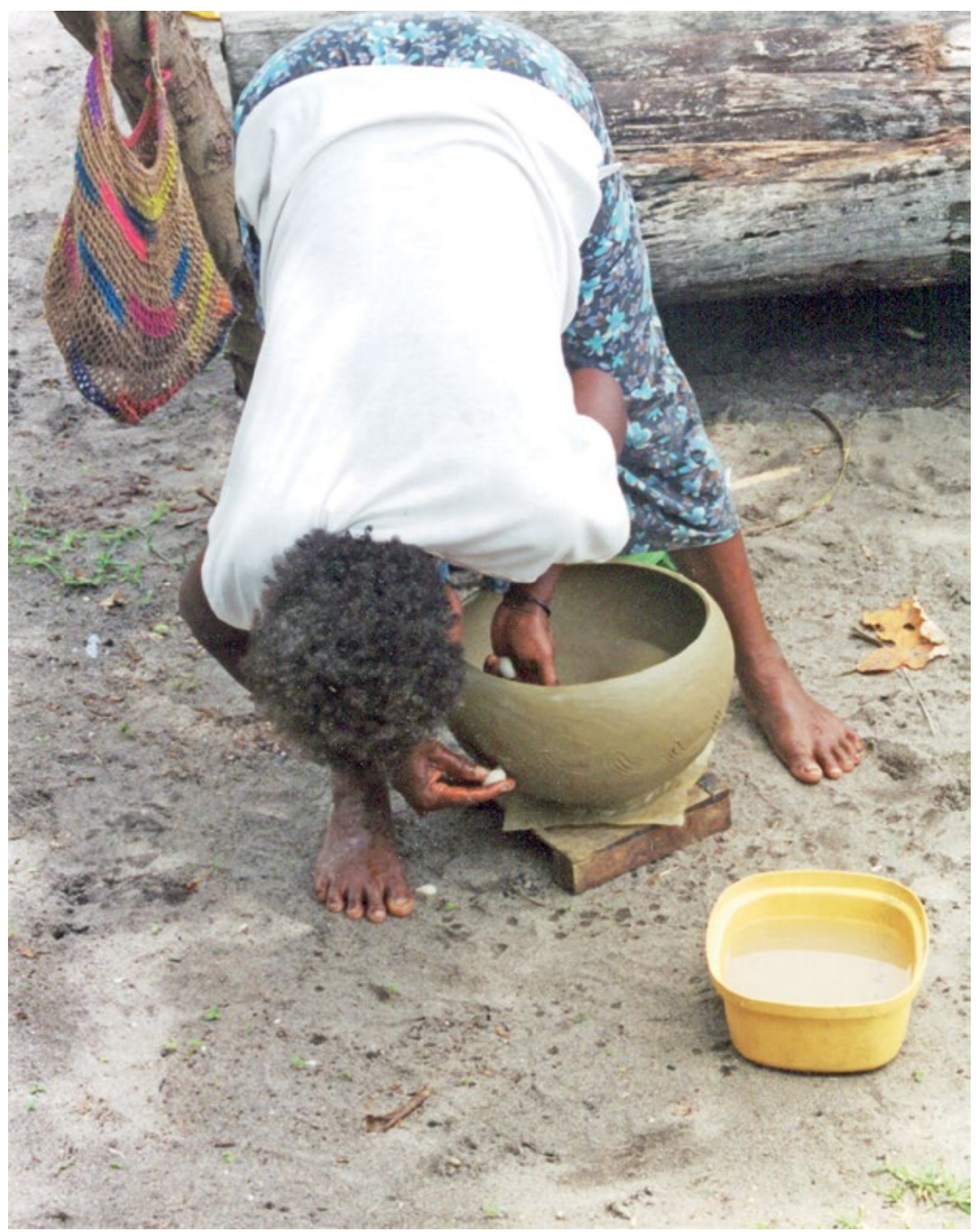

Figure 20. Potter applying design elements to her pot with a shell

Source. Photographed by Elizabeth Bonshek, 2002 
All pots are made in the same way. Clay is rolled into a solid cylindrical shape, the dimensions of which determine the size of the final nokwat (pot). ${ }^{10}$ The cylinder shape is placed on its end, and the potter pushes the sides of the clay downward, forming a shape similar to an upside down mushroom. The sides of the upturned mushroom head are made firm, and the potter then removes portions from the 'stem', which she rolls into coils and then applies to the rim of the upturned 'mushroom'. The potter continues to take clay from the centre of the stem to build up the sides of the pot until the stem is used up, at which point the rudimentary shape of the pot has been achieved. ${ }^{11}$ Once the form she desires is achieved, the potter leaves the pot to dry and then refines its shape using a paddle, and scrapes it to thin out the sides. When ready, the distinctive design is applied by pressing tiny coils into the surface of the pot, creating a series of wavy lines in curvilinear patterns. The body of the pot may be decorated in this way too, or if destined for exchange, have incised patterns on the body rather than applied motifs. Potters often stand while making their pots (although elderly potters may choose to sit) and this is a distinctive feature of Wanigela women's technique (Figures 20 and 21).

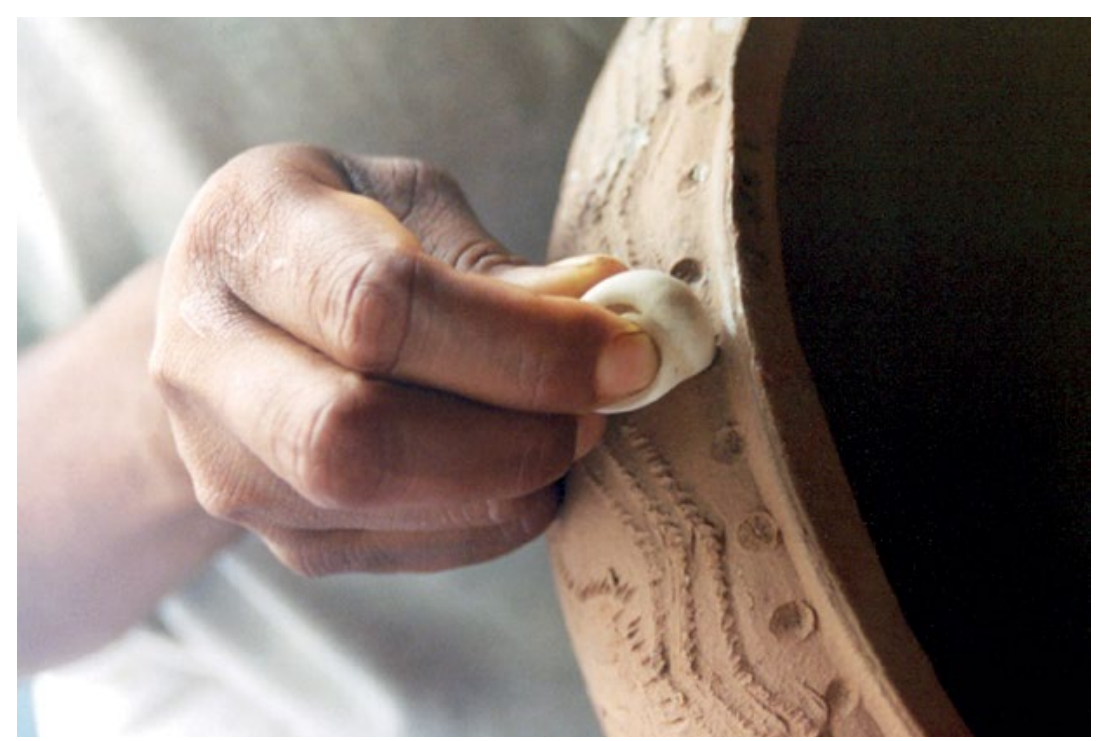

Figure 21. Application of designs while seated

Source. Photographed by Elizabeth Bonshek, 2002

10 Nokwat is the word for both a pottery vessel as well as the 'clay', the material it is made from.

11 Margaret Tuckson comments that this method 'has the advantage of keeping the clay in the centre at an even dampness for easy rolling of coils' (Specht, May and Tuckson 2001, n.p.). 
While all pots are made in the same way, they are not all destined for exchange. Pots with intricate applied patterns covering the body are kept out of the exchange network, although they might be given away as gifts. Such highly decorated pots are not readily visible in people's houses, but they may be brought out with some pride if interest is shown in them. These 'heirloom' pots often carry clan designs, and as such they manifest a connection between the pot, its owner and his or her clan identity. At the turn of the twentieth century, Percy Money, based at the Anglican Mission, photographed clan pots placed next to burial sites. In 2002, pots continued to mark grave sites in the cemetery (Figure 22), but in some cases the design has been replaced by the name of the deceased. ${ }^{12}$

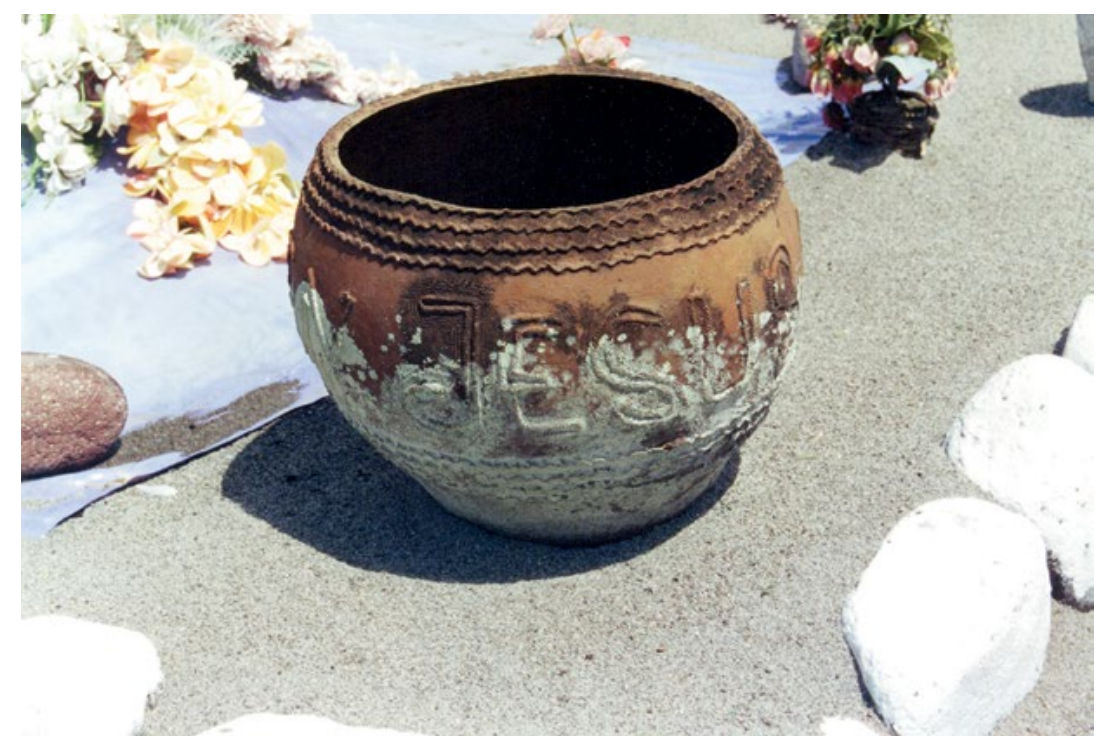

Figure 22. A 'flower pot' placed beside a grave in the cemetery at Wanigela. The potter has written 'JESUS' on one side. In former times, a clan design was used. The white stones in the foreground mark the perimeter of the grave. Bright plastic flowers cover the grave

Source. Photographed by Elizabeth Bonshek, 2002

12 This is perhaps an incidence of the 'graphicalization of meaning' in contemporary Wanigela. For a comparison see Michael O’Hanlon's work (O’Hanlon 1995). 


\section{A changing tradition}

In former times, men exchanged baitab nokwat for feathers with people inland, and for obsidian flakes and shell valuables with people living on the coast at Cape Vogel (Egloff 1974, 1979: 77; May and Tuckson 2000; Schwimmer 1967, 1979). Men travelled southwards towards Milne Bay on long-distance expeditions, which lasted for weeks, organised along clan lines. They went to exchange baitab nokwat for strings of ground shell disks known as nunug (one baitab nokwat was exchanged for 20 nunug). Nunug formed a part of bride-price payments, which all Wanigela families needed, and also body decoration for particular clans (Bonshek 2005, 2008). Nunug were bestowed upon both young men and women at 'firstborn' initiations (aabo), in which the mother's brother decorated his niece or nephew. The wearing of nunug, or their possession, was therefore associated with attaining adult status. Once decorated, a boy or girl was able to participate in dances, the prelude to amorous relationships and 'marriage'. Men and women needed baitab nokwat to obtain the necklaces required for their first-born sons and daughters to move into a marriageable status within society, and to celebrate their passage into a new stage of life. The first-born children performed this rite of passage for their younger siblings.

I met only two men who had memories of nunug expeditions, one of whom had taken part in such an event. He had been about 14 years old at the time, and thought it was the last of his clan's nunug expeditions. (He thought it must have occurred around 1947 to 1950 because the event followed shortly after the conclusion of World War II.) He also thought this was possibly the last nunug expedition made by any of the 50 or so clans living in Wanigela.

The acquisition of nunug brought renown to the men who acquired them. Participation by a young man in nunug expeditions was a mark of his adult status (boys did not go on such expeditions). Wanigela men, therefore, depended upon the skills of their wives, mothers and grandmothers in making the pots used to obtain nunug. Women's work in the form of baitab nokwat was therefore essential for the acquisition of nunug and formed an essential part of the family's cultural capital and a requirement for cultural reproduction in Wanigela (see also Weiner 1977). ${ }^{13}$

13 Alongside the transaction of baitab nokwat for nunug, Wangelan men exchanged sago for pigs, and a particular type of banana (ogi darag). 
However, there is no longer a common understanding of the value of pottery making and pot use throughout the community regarding pots used in the home, for ceremonies or for exchange. While the process of commodification of pots for cash has an unclear history, it is certain that prior to independence, and continuing into the mid-1990s, the Anglican Mission assisted in the export of pottery (both baitab nokwat and 'flower pots') for sale in Port Moresby and Popondetta. Today, this outlet is no longer viable, nor is there government infrastructure to facilitate moving pottery out of Wanigela for sale. But potters do sell baitab nokwat and 'flower pots' when they can. They take baitab nokwat to the market in the Maisin village, Uiaku (11 kilometres away) or to the Korafe village market in Tufi. Getting pots to the provincial capital Popondetta or to the national capital, Port Moresby, is an attractive idea: a baitab nokwat that might possibly sell in Wanigela for K5 (at the market held at the airstrip) can be sold for K20 'in town'. However, the potter must have the opportunity to get the pots out of Wanigela first, and this generally means having family networks living away from the village. At K20 a piece, plus the cost of getting pots to the external markets, pottery sales do not constitute a reliable or significant income (Bonshek 2008). Nonetheless, some women see such sales as an opportunity that provides much wanted income.

In 2000-03 very few elderly women still produced pots in large numbers for themselves or their family members, or as commissions (Bonshek 2008). In contrast to past practice, novice potters were mostly married women, not young girls. Residing with their husband's family, they looked to their mothers-in-law and grandmothers, not their mothers, for instruction. The contemporary mode of transmission of pottery knowledge has implications for the continued transmission of clan designs, as daughters are no longer exposed to clan knowledge pertinent to the designs of their natal clan. For the men and women of senior generations, while knowledge about pot making and designs was not articulated as wealth, clearly pots manifest economic, cultural and social value (in Bourdieu's [2000] sense of 'value'; and Weiner 1977).

While men's exchanges for nunug are a thing of the past, some Wanigela women do continue to exchange baitab nokwat, sometimes in large numbers. While barkcloth, string bags and mats are exchanged one for one, in 2002, 30 pots were exchanged for a small canoe, and 60 pots for a pig needed for a church celebration. In both these cases, women negotiated these exchanges themselves. But it is quite acceptable for a family member 
to transact pots on a woman's behalf and, equally, a woman might supply pots for her family members to transact on their own account. As the expedition illustrated, most exchanges occur through already established social relations or in conjunction with these. However, as demonstrated through the negotiations on Violet's verandah, it appears that the nature of the social relations of exchange might be on the verge of transformation. These transformations became apparent via the expectations surrounding the exchanges that occurred on the expedition, which in turn reflected 'shifting regimes of value' (Appadarai 1986). The changes encountered on the expedition, occurring at the local level, have their origins in regional and international conservation movements, and are manifest in the reconstitution of 'artefacts' into 'art' from the perspective of international non-government organisations and prospective art buyers and dealers.

\section{Shifting regimes of value}

Arjun Appadurai (1986) uses the concept of a commodity's trajectory to describe the potential uses an object (commodity) might have in any given social context. Using this framework, I propose that pots move along a number of different trajectories: they may be kept for domestic use for cooking; they may appear at ceremonial occasions such as feasting when they are used in presentations of cooked food; they may serve to display clan identity; they may be treasured as material connections with deceased family members; they may be given away as gifts; and they may enter the exchange network. In the last case, baitab nokwat form important components in the extensive regional exchange network operating in the Collingwood Bay area. But what is the nature of their value in regional exchange?

Appadurai argues that 'economic exchange creates value' and that 'value is embodied in the commodities that are exchanged ... rather than in the forms or functions of exchange' (1986: 3). Adopting this position, it is the social context of the exchange of baitab nokwat in which Wanigelan women engage (their 'commodity situation' [Appadurai 1986: 13]) that is important. In the following discussion, attention to the commodity candidacy of baitab nokwat emerges through the example of the pot exchange expedition, especially in relation to an interpretation of the suggestion that a pot be sold for K44 as a 'diversion'. Here, as Appadurai suggests, a 'diversion' is a departure from usual practice, thus carrying with it the possible development of a new standard. 
For Appadurai, the commodity candidacy of a thing refers to the 'standards and criteria (symbolic, classificatory, and moral) that define the exchangeability of things in any particular social and historical context' (1986: 14). Furthermore, objects might circulate through or across differing 'regimes of value' in space and time (4). For Appadurai, the attractiveness of this phrase lies in its flexibility-it need not presuppose 'a complete cultural sharing of assumptions' concerning the transaction of 'commodities', but 'such regimes of value account for the constant transcendence of cultural boundaries by the flow of commodities, where culture is understood as a bounded and localized system of meanings' (1986: 15).

The interactions between the potters and their Maisin counterparts in this case is interesting because they display an overlapping, or overlaying, of 'boundaries'. As suppliers of pottery, the potters are Wanigelans: Wanigelans have sole access to the clay and pottery making is unique to the Wanigela villages. As such, all potters are Wanigelans (although not all Wanigelans are potters). But as Wanigelans, potters also identify themselves as belonging to what is in fact one of a number of discrete villages, as speakers of one of four tok ples languages and belonging to one of the 50 or so clans that reside there. ${ }^{14}$ As the suppliers of pots within a regional network of exchange, Wanigelans also claim a place in a broader regional stage: they are from Collingwood Bay and they participate in exchanges of some antiquity with their neighbours. Depending on historical connections, specific events and the agents involved, potters continuously shift their alliances. They might identify with specific tok ples speakers and have particular village affiliations, but also identify as being Wanigelan or being part of a wider Collingwood Bay-wide exchange network (Bonshek 2005). Within Wanigela, the idea of a 'bounded' cultural group is highly problematic, as people differentiate themselves on the basis of language and clan within the context of any specific activity.

Disregarding for a moment the problematic associations of positioning oneself within a local (language and village) context and subsequently in regard to the outward-moving ripples of connection (from village to region constituted by history and the passage of time), the transactions during the expedition took place within existing social networks. The women who exchanged with one another on this occasion could trace family

14 Each of the 50 or so clans have their own histories of origin and migration into Wanigela. 
connections through intermarriage, descent and residence. In addition to these kinship connections, as active members of the Wanigela Mothers' Union and the Airara Women's Union, the women were connected via the structural organisation of the Anglican Church. Two of the women at least had also previously lived in Airara: one when her husband had been posted to the area as a teacher, and the other when her husband was stationed at the medical outstation there. 'Strangers' were introduced through these pre-existing social links and networks (Strathern 1988; Weiner 1977).

The potters entered into their transactions with a number of expectations revolving around the attributes they felt constituted an acceptable piece of barkcloth for exchange. At the first village, the women entered into negotiations without seeing the barkcloth on offer. Their expectations became clear (to the outsider) when the unexpected occurred: the cloth was not completed-it had not been painted. Further, in one case the size was not big enough to accommodate an adult man or woman. A woman's barkcloth must be a large rectangle, worn wrapped around the waist one-and-a-half times, and allowing room for trimming the fringe (the customisation of the cloth with an individual's clan design). A man's barkcloth must be long and narrow, proportioned so as to be worn as a loincloth, with plenty of room at either end to allow for fringes to be cut. (The potters did not judge the barkcloth on the basis of the designs they carried.)

The Wanigela women were unhappy about accepting unfinished cloth because they were anxious about whether it would be completed on time: they wanted to leave Airara with their barkcloth in hand. Coming back to Airara was not an option for them as they did not have ready access to a canoe in which to return. The Wanigela ladies would be reliant upon the Airara women to bring the barkcloth to Wanigela. But at the same time, while worried about these matters, Carol explained to me (as much as to reassure herself it seemed to me at the time) that the Airara women knew how the 'bush ladies' lived. They (the Airara women) had visited in 2001, so 'the Airara women knew that the Bush ladies did not have canoes'. So the rationale for proceeding with accepting unfinished cloth was presented to me as one based on the Airara women's familiarity and prior knowledge of Wanigela's women's circumstances. And, in fact, the barkcloth did arrive the following week. 
In Appadurai's terms, the Wanigela women can be understood as viewing the barkcloth and pots as being in a standard relationship with one another - a relationship built upon precedent. From the Wanigela women's point of view, there were common assumptions about what constituted an appropriate exchange regardless of the specific difficulties that arose.

Using Appadurai's framework, the baitab nokwat were 'commodities by destination': they were objects made by potters with the intention of using them in exchanges (1986: 15). Their circulation in the specific case related here reflected 'a shifting compromise between socially regulated paths and competitively inspired diversions' (Appadurai 1986: 17). The interaction on Violet's verandah, through which arose the possibility of selling instead of exchanging a barkcloth, represented such a 'diversion': for the potters it introduced altered assumptions about what the exchange of pots for barkcloth constituted. Violet's offer lay beyond the Wanigela women's anticipations; it originated outside the then current regimes of value (the exchange of one pot for one barkcloth). In this case, the Wanigela women responded to the diversion by ignoring it.

However, it is important to recognise that the establishment of a cash value is not, of itself, unacceptable to the potters; as mentioned, Wanigela women do sell their baitab nokwat. Of all the pot transactions I recorded between 2001 and 2003, 25 per cent were concerned with pots made for a cash sale. While this appears a sizeable percentage (a quarter of all the transactions), in fact only a small number of pots ( 10.6 per cent of the total number of pots transacted) were sold or earmarked for sale. They were sold at markets in Wanigela, Tufi or Uiaku. The highest price for one pot was K20, which was considered a very good price, and not a price that a 'local' would be expected (or asked) to pay. It was the outsider's price. Pots appeared for sale only rarely in the Wanigela market during 2001 to 2003, and I inadvertently caused confusion amongst the potters I knew by buying one at $\mathrm{K} 20$.

At the time I did not know the potters very well, and I had simply thought the pot on sale was very beautiful. After I purchased it, two potters I knew visited me and quizzed me on why I had made the purchase. They were very perplexed by what I had done-all that was necessary to get such a pot was to ask one of the potters I knew to make it. The acquisition of pots from someone I was not connected to, and the payment of such a large sum, was not compatible with the social networks and obligations that were developing around me (and of which I was obviously unaware until 
then). Also, for them, the pot was simply a pot. While I had particularly liked the pot I bought (the design on it was especially to my liking) my inquisitors were not concerned with what I saw as 'quality' or my aesthetic sense regarding pots and the motifs they carried. Any potter could supply me with a baitab nokwat, but a potter I was connected with should be the woman to make it for me (Bonshek 2015).

I suggest that there are two aspects that might be considered in unravelling the impact of a request for a cash price. First, as demonstrated, from the Wanigelan perspective, a cash value belongs in another regime of valuesthat of sales to outsiders, not exchanges between people in Collingwood Bay. So, when Violet asked for a cash price while sitting on her verandah, for the Wanigela women her offer was outside the regime of value associated with the regional exchange network: the cash value disrupted the values attendant upon exchange (a standard size of a pot, for an appropriately sized barkcloth). In Appadurai's terms, the existing social relationship that constituted the exchange was altered.

Second, while not verbally corroborated by Wanigelans, it is, I think, suggestive that all exchanges concerning pots that I encountered comprised exchanges of either one for one, or exchanges of pots in multiples of five with 20 as a base. In the Ubir counting system, five is termed 'one hand', 10 is 'two hands', 15 is 'two hands and a foot', and 20 is a 'man' (orot). Thus the numbers one to 20 may be conceived of as a unity or the completion of a whole: 'one man'. ${ }^{15}$ Other exchange equivalences involving pots are recorded in Table 1.

Table 1. Exchange equivalence of pots with other items in 2001-03

\begin{tabular}{|lll|}
\hline Baitab nokwat & & Exchanged for \\
\hline 1 baitab nokwat & $=$ & 1 barkcloth \\
\hline 1 baitab nokwat & $=$ & 1 string bag \\
\hline 1 baitab nokwat & $=$ & 1 pandanus mat \\
\hline 1 baitab nokwat & $=$ & 20 shell necklaces \\
\hline 30 baitab nokwat (or $1 \frac{1}{2}$ men) & $=$ & 1 canoe \\
\hline 60 baitab nokwat (or 3 men) & $=$ & 1 pig \\
\hline 1 baitab nokwat & $=$ & K20 at the 'town price' \\
\hline 20 baitab nokwat (or 1 man) & $=$ & gift (of 20 pots) associated with bride price \\
& & (but not itself constituting bride price)
\end{tabular}

15 The expression for a singular thing is kaitomom, and 20 is kaitomom orot (one man). 
So while Wanigela women do sell pots, Violet might have moved into unrecognised 'numerical territory' when she asked for K44. I suggest that, from a Wanigelan perspective, the sum itself was odd, as well as entering contentious territory in terms of transforming an existing regime of value into something else. The price of her barkcloth had been set by MICAD. But in asking the MICAD price, she opened up the possibility of denying the value associated with longstanding historical exchanges and, in doing so, potentially denying the social nature of the exchange itself. The request for cash in this context compromised both the quality of social relations surrounding exchange, and disturbed established regimes of value. In Appadurai's terms (1986: 29-41), the exchange of what were once commensurate 'desires' became, on this occasion at least, incommensurate, as one partner's expectations shifted.

This investigation is constrained to the potter's viewpoint. The 'diversion' originating from the Maisin end of the exchange reflected changes caused by an 'aid project' initiated by Greenpeace. For my purposes, Greenpeace is viewed simply as a globalised organisation, whose aims are targeted to its own interests (specifically the prevention of logging in the region). The operations of Greenpeace in Collingwood Bay have been detailed elsewhere (Barker 2008; and Hermkens 2013) and are not of central importance to this chapter, except for the flow-on effect experienced by the potters as exemplified during the expedition. But it must also be remembered that the case presents the responses of older women in the community, who may not represent the views of younger women. The senior women were demonstrating how pottery exchange works, but in so doing their encounter with local incursions of global forces revealed insights into changing perceptions of wealth and value.

The events also present a dilemma for those who are confronted with serious challenges in their acquisition of cash. The senior potters were not disconnected from, or undesiring of, cash. But their own avenues for earning cash through pottery production had not been developed either by themselves or outsiders. Some felt that the developments in barkcloth production, as a result of Greenpeace's activities in Collingwood Bay to create a sustainable industry for the Maisin (see Hermkens this volume), ignored them. 


\section{Global impacts - transforming artefacts into art}

Prior to PNG's independence, Sister Helen Roberts, the nursing sister who had been running the Anglican Church's medical centre in Wanigela for a considerable number of years, provided an irregular outlet for the sale of both barkcloth and pots (Barker 2007: 77). These exports of 'artefacts' from Collingwood Bay to outsiders is not well documented, but follows from the supply of ethnographic items to museum collections in Australia, England, Scotland and elsewhere dating to the turn of the twentieth century (Beran and Aguire 2009; Bonshek 1989; and Hermkens 2013). An early assessment of the potential for commercial sales of barkcloth and pots in the 1960s did not view the situation for pots very favourably when compared to barkcloth - pots were relatively heavy and also fragile (Schwimmer 1967, 1979).

Since 1996, as a result largely from the work of Greenpeace International, Maisin barkcloth has been commoditised for western audiences as 'art' and sold through MICAD (see further Hermkens this volume). As John Barker comments, barkcloth was attractive to the conservation movement in a number of ways: it was 'sustainable', easy to ship, a symbol of continuity of tradition, iconic of Oceanic art forms, and importantly it represented women's work (Barker 2008: 191). During this period, MICAD collected barkcloth from all the Maisin villages, set a price according to size, and sold the cloth in towns within PNG as well as overseas. It is one of these pieces of barkcloth that had not been sold via MICAD that Violet was trying to move on.

Perhaps a victim of the 'West's' ideological distinction between art and craft, Wanigela pottery has not made the transformation into art, from the 'art world' point of view (but see Beran and Aguire 2009). Pots remain largely objects of 'material culture' that provide museums with evidence of how cultural practices and contemporary cultural values might have changed or continue over time. My own acquisition of 13 Wanigela pots for the Australian Museum, Sydney, in 2003 was destined for a natural history museum holding extensive anthropological collections that provided the potential to analyse continuity and change (Bonshek 2015). Under their contemporary collection development policies, these pots are now conceived of primarily as 'cultural heritage' and 'cultural collections' rather than as 'art' (Australian Museum 2014). 
To my knowledge, Wanigela pots have been exhibited as 'art' on two occasions only, but not promoted as artwork in terms of sales. First during the 1960s, at the time that artist Patricia May and potter Margaret Tuckson made a substantial collection of pottery from PNG (May and Tuckson 2000) for the Australian Museum, Sydney, and some 40 years later, in 2001, at the Djamu Gallery, a former art gallery venue at Australian Museum's Customs House site (Specht, May and Tuckson 2001). Both exhibitions drew upon the same collections held at the museum. The Wanigela component was comprised of pots collected between 1904 and 1910 by Percy Money-a lay missionary with the Anglican Church who made an extensive collection of a broad range of material culture from Wanigela (Bonshek 1989)—and some 50 years later from the collection made by May and Tuckson. The second exhibition promoted an artistic interpretation in its display method. However, such transformations of the objects' status (art vs artefact [Myers 2001]) were played out within the museum's field of cultural production with no direct effect or involvement of the Wanigela potters.

In contrast, in the 1990s, barkcloth was subject to a differing trajectory on the global stage. Maisin barkcloth has been displayed as art in exhibitions in the United States of America (Barker 2008), and has been produced and, importantly, priced for sale and display in international exhibitions. Since 2006, barkcloth from neighbouring areas to the north have been sold as 'art ${ }^{16}$ and exhibited in private and public galleries. ${ }^{17}$

The success, or otherwise, of sustainable barkcloth production for Maisin villages is discussed elsewhere (Barker 2008; Hermkens this volume); however, within Wanigela, where there is a history of exchange relationships of some continuity documented in European records over 100 years ago, the changes in barkcloth production and pricing by MICAD have had disrupting flow-on effects. While barkcloth production has been placed centre stage in the transformations of objects from items of material culture to art through both national and international exposure, pottery remains largely embedded within local regimes of value and as a 'craft' to any potential 'art' buyer.

16 For example, Ömie Artists (Inc.). Online: www.omieartists.com (accessed 28 June 2015).

17 For instance see Wisdom of the Mountain. Art of the Ömie exhibition held at National Gallery of Victoria, 27 November - 21 March 2010. Online: www.ngv.vic.gov.au/exhibition/wisdom-of-themountain (accessed 28 June 2015). 
The development of a mechanism for Maisin to earn cash through the sales of barkcloth has not gone without notice in Wanigela. While most women in Wanigela do not understand the details of how MICAD barkcloth sales operated at the time, or the connection with Greenpeace, they saw Maisin women making money, and they experienced through Violet a preference for cash rather than exchange. But Wanigela women too want to have cash, and consequently some viewed developments in Maisin barkcloth sales with envy. This unhappiness spilt out in comments that 'Wanigelans own barkcloth too', that 'the Maisin stole barkcloth making from Wanigela using sorcery'. I was told that during the 1950s, Maisin sorcery had caused all the mulberry trees in Wanigela to die, and that the designs that are applied to the barkcloth 'belong to Collingwood Bay, not just to the Maisin'. These women drew upon regional identities, not village affiliations, to express their frustration.

Violet's offering of her barkcloth for sale at the MICAD price of K44 not only took barkcloth outside the regional network of a one-to-one relationship between Wanigela pots, Maisin barkcloth, Miniafia string bags and mats in which the women customarily operated, but strayed into an avenue of cash generation from which Wanigela women felt excluded.

\section{Conclusion}

Between 2001 and 2003, the production and circulation of baitab nokwat by senior women in Wanigela represented a continuity of tradition, in terms of both a manufacturing technique and in the social relations in which these processes are enmeshed. Pots were not traded for food, which Wanigelans do not need to import (cf. Arifin 1991: 375; May and Tuckson 2000; Welsch and Terrell 1998). Women's production of pottery was not connected solely to utilitarian needs (where 'demand' and 'desire' are understood as natural, fixed and transcultural states or needs [Appadurai 1986: 29]). According to both senior men and women, making pots was emblematic of being Wanigelan.

In the past, both men and women needed baitab nokwat to fulfil social obligations. These pots were essential components for exchange expeditions made by men to obtain valuable nunug (shell necklaces) essential for aabo (first-born ceremonies) and kekes (bride price). Special pots (sabed) were also used in feasting that took place between clan groups. The latter are no longer made, and the men's voyages for exchange 
terminated in the mid-1940s. It appears that further change is also on the horizon for the women's use of pottery. Women increasingly want to sell pots for cash, but have no real market to sell through: they do not have easy access to provincial towns and, since independence, tourists no longer visit Wanigela. But while women may want to, and do, sell pots for cash in some contexts (pots may be commissioned, or taken to market and sold), their replacement for cash in exchanges with local neighbours is not welcomed by older Wanigela women.

For these women, it is exchange with the Maisin women that is of value (Appadurai 1986: 28). The transfer of MICAD prices by the Maisin women to the sphere of exchange holds the potential to undermine what have long been commensurate values. For the Wanigela women on the trip, what Appadurai would call the 'commodity candidacy' of the pots holds the potential for being altered and the very possibility of this being the case is disruptive. In Appadurai's terms, the Wanigelan's view of the 'cultural framework' of the exchange, the conventions that govern the exchangeability of things (one-for-one exchange; or a calculation based on 20), were being attenuated as one party to the exchange appeared to be on the verge of withdrawing from this convention; hence values were in danger of becoming 'unyoked' (1986).

The commoditisation of Maisin barkcloth therefore poses a real problem for Wanigela women. It remains to be seen whether the Maisin will push further down the path of commoditisation in their exchange transactions with their Collingwood Bay neighbours, or whether commoditisation will be confined to sales within MICAD operations outside the region. A crucial factor will be how desirable Wanigela pots remain for Maisin, and whether Wanigela potters will set their price in cash.

For now, older women are happy supplying pots for their relatives to sell. But younger women, who have begun to consider making pots as a means to improve their economic standing through earning cash, may not wish to give away their labour for the benefit of extended family members or for the maintenance of the social relations deemed so important by the potters on the expedition. Since 2003, there has been one pot-making project in Wanigela, based in the Onjob village of Koreaf, which has attempted to revalue pot making. The instigator of the project articulates the promotion of pottery manufacture as something that defines Koreaf women's identity, and as a practice that supports Onjob tradition. He makes a distinction between Onjob identity and Wanigela identity 
in his promotion of pot making, and was inspired by his own observations of how MICAD has worked with the Maisin in developing barkcloth for commercial production. But his project reveals a different kind of transformation: the objectification of pot making as a cultural practice bound to an expression of cultural identity (Miller 1987).

The manufacture and exchange of baitab nokwat in Wanigela is not yet a dying tradition, but it is in a fragile state. It might be recontextualised as an economic activity providing access to the cash economy and thus move away from an exchange economy; or it may be revalued as an objectified product of Wanigelan tradition, or indeed both. For now, while unchanged in visual appearance, baitab nokwat conceal fluctuations in the social relations surrounding the production and use of these distinctive, and regionally important, objects of women's wealth.

\section{References}

Appadurai, Arjun (ed.). 1986. The Social Life of Things: Commodities in Cultural Perspective. Cambridge: Cambridge University Press.

Arifin, Karina. 1991. 'Social Aspects of Pottery Manufacture in Boera, Papua New Guinea'. Bulletin of the Indo-Pacific Prehistory Association 11: 373-387. DOI: 10.7152/bippa.v11i0.11401.

Australian Museum. 2014. Cultural Collections Acquisition Policy 20142017. Online: www.australianmuseum.net.au/Our-policies (accessed September 2014).

Barker, John. 2004. 'Between Heaven and Earth: Missionaries, Environmentalists, and the Maisin'. In Globalization and Culture. Change in the Pacific Islands, ed. Victoria Lockwood, pp. 439-459. Upper Saddle River, NJ: Pearson, Prentice Hall.

(ed.). 2007. The Anthropology of Morality in Melanesia and Beyond. Aldershot: Ashgate.

- 2008. Ancestral Lines: The Maisin of Papua New Guinea and the Fate of the Rainforest. Peterborough, Ontario: Broadview Press.

Beran, Harry and Edward Aguire. 2009. The Art of Oro Province. A Preliminary Typology. Sydney: The Oceanic Art Society. 
Bonshek, Elizabeth. 1989. Money, Pots and Patterns: The Percy Money Collection of Bark Cloth and Pottery held at the Australian Museum. MA thesis. St Lucia: University of Queensland.

—. 2005. 'The Struggle for Wanigela: Representing Social Space in a Rural Community in Collingwood Bay, Oro Province, Papua New Guinea'. PhD thesis. Canberra: The Australian National University.

— 2008. 'When Speaking is a Risky Business: Understanding Silence and Interpreting the Power of the Past in Wanigela, Oro Province, Papua New Guinea'. Journal of Material Culture 13(1): 85-105. DOI: $10.1177 / 1359183507086220$.

- 2015. 'Ethics and Collecting in the "Postmodern" Museum: A Papua New Guinea Example'. In The Ethics of Cultural Heritage, ed. Tracy Ireland and John Schofield, pp. 145-164. New York: Springer Press.

Bourdieu, Pierre. 2000. Pascalian Meditations. Stanford, CA: Stanford University Press.

Busse, Mark, Nick Araho and Ivuyo Baiva. 1991. Traditional Trade and Migration among the Daga: Report of a Research Trip through the Owen Stanley Mountains of Central and Milne Bay Provinces. Port Moresby: National Museum of Papua New Guinea.

Egloff, Brian. 1974. 'Contemporary Wanigela Pottery'. Occasional Papers No.2, Anthropology Museum, pp. 67-79. St Lucia: University of Queensland.

-1979. Recent Prehistory in South East Papua. Canberra: The Australian National University Press.

Hermkens, Anna-Karina. 2013. Engendering Objects. Dynamics of Barkcloth and Gender among the Maisin of Papua New Guinea. Leiden: Sidestone Press.

Ireland, Tracy and John Schofield (eds). 2015. The Ethics of Cultural Heritage. New York: Springer Press.

Lockwood, Victoria (ed.). 2004. Globalization and Culture. Change in the Pacific Islands. Upper Saddle River, NJ: Pearson, Prentice Hall. 
May, Patricia and Margaret Tuckson. 2000 [1986]. The Traditional Pottery of Papua New Guinea. Adelaide: Crawford House Publishing.

Miller, Daniel. 1987. Material Culture and Mass Consumption. New York: Basil Blackwell.

Myers, Fred (ed.). 2001. The Empire of Things: Regimes of Value and Material Culture. Santa Fe: School of American Research Press.

O'Hanlon, Michael. 1995. 'Modernity and the "Graphicalization" of Meaning: New Guinea Highland Shield Design in Historical Perspective'. The Journal of the Royal Anthropological Institute 1(3): 469-493. DOI: 10.2307/3034571.

Patterson, Mary and Martha Macintyre (eds). 2011. Managing Modernity in the Western Pacific. St Lucia: University of Queensland Press.

Schwimmer, Ziska. 1967. Report on Handcrafts of the Northern District. Port Moresby: Department of Business Development.

- 1979. 'Tapa Cloths of the Northern District'. Pacific Arts Newsletter 9: 6-11.

Specht, Jim, Patricia May and Margaret Tuckson. 2001. Sospen Graoun. Pottery from Papua New Guinea. Exhibition catalogue, Sydney: Australian Museum.

Stark, Miriam T. (ed.). 1998. The Archaeology of Social Boundaries. Washington, DC: Smithsonian Institution Scholarly Press.

Strathern, Marilyn. 1988. The Gender of the Gift: Problems with Women and Problems with Society in Melanesia. Berkeley: University of California Press.

Weiner, Annette. 1977. Women of Value, Men of Renown: New Perspectives in Trobriand Exchange. Brisbane: University of Queensland Press.

Welsch, Robert and John Terrell. 1998. 'Material Culture, Social Fields, and Social Boundaries on the Sepik Coast of New Guinea'. In The Archaeology of Social Boundaries, ed. Miriam T. Stark, pp. 50-77. Washington, DC: Smithsonian Institution Scholarly Press. 
This text is taken from Sinuous Objects: Revaluing Women's Wealth in the Contemporary Pacific, edited by Anna-Karina Hermkens and Katherine Lepani, published 2017 by ANU Press, The Australian National University, Canberra, Australia. 